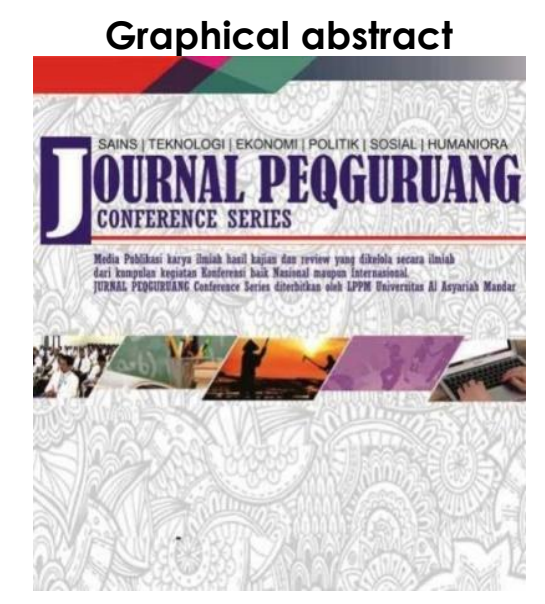

\section{EFEKTIVITAS BANTUAN KARTU PRAKERJA TERHADAP PEREKONOMIAN MASYARAKAT DI MASA PANDEMI COVID-19 DI DESA PATAMPANUA KECAMATAN MATAKALI KABUPATEN POLEWALI MANDAR}

\author{
${ }^{1 *}$ Mardewi, ${ }^{2}$ Saifuddin, ${ }^{3}$ Suardi Kaco \\ ${ }^{123}$ Program Studi Hukum Ekonomi Syariah Fakultas Agama \\ Islam Universitas Al Asyariah Mandar
}

Corresponding author mardewiewi@gmail.com

\begin{abstract}
The purposes of this study are 1) To find out how the process of preemployment card assistance to the community's economy during the Covid-19 pandemic in Patampanua Village, Matakali District, Polewali Mandar Regency. 2) To find out how the effectiveness of the preemployment card in the midst of the Covid-19 pandemic on people's income in Patampanua Village, Matakali District, Polewali Mandar Regency. This type of research is a qualitative research. The location of this research is in Patampanua Village, Matakali District, Polewali Mandar Regency. The data sources in this study are primary data sources and secondary data sources. Data collection methods consist of observation, interviews, and documentation. Data analysis and processing techniques used data reduction, data presentation and conclusion drawing, while checking the validity of the data used method trangulation and source triangulation. The results of this thesis research entitled the effectiveness of pre-employment card assistance on the community's economy during the Covid-19 Pandemic Period in Patampanua Village, Matakali District, Polewali Mandar Regency, namely the process of pre-employment card assistance to the community's economy during the COVID-19 pandemic in Patampanua Village has two stages and effectiveness Pre-employment card assistance to the community's economy during the COVID-19 pandemic in Patampanua Village, Matakali District, Polewali Mandar Regency was less effective because people only used pre-employment card assistance to meet their daily needs and only received incentives for four months, in addition, the pre-employment card program This can only be used for people who have sufficient knowledge of technology and information (IPTEK). This is because the registration and implementation of this pre-employment card program uses the online method. So that people who do not know anything about science and technology will be constrained by the pre-employment card program.
\end{abstract}

Keywords: Effectiveness, Pre-Employment Card Assistance, Covid-19 Pandemic Period

\section{Abstrak}

Tujuan Penelitian ini adalah 1) Untuk mengetahui bagaimana proses bantuan kartu prakerja terhadap perekonomian masyarakat di masa pandemi Covid-19 di Desa Patampanua Kecamatan Matakali Kabupaten Polewali Mandar. 2) Untuk mengetahui bagaimana efektivitas kartu prakerja di tengah pandemi Covid-19 terhadap pendapatan masyarakat di Desa Patampanua Kecamatan Matakali Kabupaten Polewali Mandar. Jenis penelitian ini merupakan penelitian kualitatif. Lokasi penelitian ini bertempat di Desa Patampanua Kecamatan Matakali Kabupaten Polewali Mandar. Sumber data dalam penelitian ini yaitu sumber data primer dan sumber data sekunder. Metode pengumpulan data terdiri dari observasi, wawancara, dan dokumentasi. Teknik Analisis dan pengolahan data menggunakan reduksi data, penyajian data dan penarikan kesimpulan, sedangkan pengecekan keabsahan data menggunakan trangulasi metode dan triangulasi sumber. Hasil penelitian skripsi ini yang berjudul efektivitas bantuan kartu prakerja terhadap perekonomian masyarakat di Masa Pandemi Covid-19 di Desa Patampanua Kecamatan Matakali, Kabupaten Polewali Mandar yaitu proses bantuan kartu prakerja terhadap perekonomian masyarakat di masa pandemi covid-19 di Desa Patampanua memiliki dua tahapan dan efektivitas bantuan kartu prakerja terhadap perekonomian masyarakat di masa pandemi covid-19 di Desa Patampanua Kecamatan Matakali Kabupaten Polewali Mandar kurang efektif karena masyarakat hanya menggunakan bantuan kartu prakerja untuk memenuhi kebutuhan sehari-hari saja dan hanya selama empat bulan mendapatkan insentif, selain itu, program kartu prakeja ini, hanya dapat dimanfaatkan bagi masyarakat yang memiliki ilmu pengetahuan teknologi dan informasi (IPTEK) yang cukup. Hal ini di karenakan pendaftaran dan pelaksanaan program kartu prakerja ini menggunakan metode Daring. Sehingga masyarakat yang tidak tahu menahu tentang IPTEK akan terkendala pada program kartu prakerja.

Kata Kunci: Efektivitas, Bantuan Kartu Prakerja, Masa Pandemi Covid-19

\title{
Article history
}

DOI: https://dx.doi.org/10.35329/ip.v3i2.2241

Received : 18 September 2021 | Received in revised form : 22 Oktober 2021 | Accepted : 19 Novemeber 2021 


\section{PENDAHULUAN}

Pengangguran adalah situasi dimana seseorang tidak memiliki pekerjaan dan ingin mendapatkan pekerjaan tapi belum mendapatkan pekerjaan tersebut. Orang yang berusia 15-64 tahun dapat dikategorikan sebagai usia angkatan kerja. Penduduk yang belum bekerja dan mencari pekerjaan masuk dikelompok penduduk angaktan kerja.Tingka persentase soal pengangguran adalah orang yang belum mendapatkan pekerjaan. Seorang pengangguran dapat orang-orang yang belum bekerja atau orang-orang yang sama sekali tidak bekerja.

Dampak dari keberadaan kartu pra kerja ini terhadap jumlah pengangguran masih belum terasa. Pasalnya, jumlah pengangguran terbuka saat ini sudah melebihi 7 juta. Belum lagi akibat krisis pandemi Covid19, para pekerja informal dan pekerja pariwisata terpaksa harus kehilangan pekerjaan setiap hari. Menurut pengamatan, selama pandemi ini, industri pariwisata dan turunannya seperti hotel menjadi industri pertama yang mem-PHK pekerja. Di sektor manufaktur, PHK belum terjadi secara besar-besaran, namun banyak perusahaan yang belum memperluas rencana perekrutannya. Ada juga langkah-langkah untuk mempercepat penyelesaian sisa kontrak yang sebenarnya. Selain itu, untuk menjaga daya beli masyarakat yang menjadi motor penggerak pertumbuhan ekonomi, bantuan tunai dinilai lebih penting daripada kartu prakerja.

Kelemahan dari kartu pra kerja adalah jumlah materi pelatihan yang tidak sesuai dengan kebutuhan. Yang kedua adalah akses digital. Seluruh proses pelatihan pra-kerja dilakukan dengan berani. Menurut data Kementerian Komunikasi dan Informatika, kecepatan akses internet di Jakarta bisa mencapai 10 Mbps, sedangkan Maluku dan banyak wilayah Papua hanya bisa mencapai $300 \mathrm{Kbps}$. Ketiga, karena prosedur di era pandemi tidak sinkron, mereka tidak bisa ikut serta mengatasi dampak pandemi itu sendiri. Dana prakerja harus dialokasikan untuk bantuan sosial atau kegiatan pemulihan ekonomi. Keempat jenis pemrograman ini juga dianggap bias kelas menengah karena sepenuhnya didasarkan pada keberanian. Diyakini bahwa kelima perusahaan ini ragu-ragu untuk mengikuti program tersebut karena kemampuan mereka belum teruji. Semuanya bermuara pada masalah ketenagakerjaan.

Untuk melihat indikator program kartu pra kerja untuk membantu masyarakat rentan COVID19 mencapai tujuannya, dapat diukur dengan efektivitas program kartu pra kerja. Hal ini dapat diukur dengan membandingkan desain panggung dengan hasil aktual yang telah dicapai. Tindakan yang dilakukan harus memadai karena tujuan tidak akan tercapai, yaitu jika tindakan tidak memadai maka bantuan tidak akan efektif.

Tinjauan pustaka sebelumnya dari penelitian ini adalah: Penelitian yang dilakukan oleh Siti Paisah dengan judul "Analisis Efektivitas Penyaluran Program
Keluarga Harapan (PKH) Dalam Penanggulangan Kemiskinan di Kecamatan Lingga Bayu Kaputaten Mandailing Natal" Fakultas Ekonomi dan Bisnis Islam Universitas Islam Negeri Sumatera Utara Medan, 2019. Penelitian yang dilakukan oleh Fatkhul Khoiriyah dan kawan-kawan dengan judul "Efektivitas Pelaksanaan Bantuan Sosial dari Pemerintah Terhadap Masyarakat Terdampak Covid-19 di Desa Gendonggarum Kecamatan Kanor Kabupaten Bojonegoro" Fakultas Syariah dan Hukum Universitas Islam Negeri Sunan Ampel, 2020. Penelitian yang dilakukan oleh Carly Erfly Fernanndo Maun dengan judul "Efektivitas Bantuan Langsung Tunai Dana Desa Bagi Masyarakat Miskin Terkena Dampak Covid-19 Di Desa Talaitad Kecamatan Suluun Tareran Kabupaten Minahasa Selatan" Fakultas Ilmu Sosial Ilmu Pemerintahan Universitas Sam Ratulangi, 2020. Adapun kegunaan dari penelitian ini secara teoretis diharapkan dapat mengembang dan menambah khazanah ilmu pengetahuan tentang pengaruh dan efektivitas bantuan kartu prakerja terhadap perekonomian masyarakat di masa pandemi Covid-dan secara praktis penelitian ini, diharapkan bisa digunakan sebagai sumber informasi dan solusi alternatif terhadap permasalahan yang dihadapi.

\section{METODE PENELITIAN}

Jenis penelitian ini adalah penelitian kualitatif. Pendekatan yang digunakan adalah pendekatan pendekatan komunikasi dan pendekatan sosialogi. Sumber data yang digunakan adalah sumber data primer dan sumber data sekunder. Metode pengumpulan data menggunakan observasi, wawancara, dan dokumentasi. Instrumen penelitian yang digunakan adalah list pertanyaan atau daftar pertanyaan kepada narasumber, perekam suara, kamera untuk mendokumentasikan dan instrumen pendukung lainnya. Teknik pengolahan dan analisis data dalam penelitian ini menggunakan reduksi data, penyajian data dan penarikan kesimpulan. Untuk menguji keabsahan data yaitu menggunakan triangulasi metode dan triangulasi sumber.

\section{HASIL DAN PEMBAHASAN}

Penelitian ini dilakukan di Desa Patampanua Kecamatan Matakali, Kabupaten Polewali Mandar, Provinsi Sulawesi Barat. Kartu prakerja adalah program pengembangan kompetensi berupa bantuan biaya yang ditujukan untuk pencari kerja, pekerja yang terkena pemutusan hubungan kerja (PHK) atau pekerja yang membutuhkan peningkatan kompetensi. Dalam situasi pandemi, pendaftaran program dan kegiatan pelatihan hanya dapat dilakukan secara daring. Ada kekhawatiran bahwa pelaksanaan secara daring dapat memengaruhi keefektifan dan pencapaian tujuan pelatihan. Penyaluran bansos juga dilakukan melalui transfer ke rekening bank atau dompet elektronik. Namun, dengan metode transfer ini, terdapat celah yang memungkinkan penerimaan bansos oleh masyarakat 
yang sebenarnya tidak terdampak secara ekonomi. Selain itu, kelompok masyarakat yang sejatinya merupakan sasaran bansos, yaitu warga miskin dan penduduk berpendidikan rendah, justru masih menghadapi masalah literasi dan kesenjangan digital.

Program Kartu Prakerja (KP) resmi diluncurkan pada 11 April 2020. Awalnya dirancang sebagai program pelatihan yang dirancang untuk meningkatkan kemampuan dan daya saing peserta. Namun, rencana tersebut kemudian ditambah dengan program bansos untuk menghindari penurunan kesejahteraan masyarakat terdampak pandemi COVID19 yang tidak tercakup dalam program bansos konvensional. Dengan dua tujuan tersebut, maka perlu dilaksanakan program kartu pra kerja untuk menjangkau 5,6 juta peserta dalam waktu persiapan yang sangat singkat hanya 1,5 bulan. kerja adalah:

Persyaratan untuk mendapatkan kartu pra

a. Warga Negara Indonesia (WNI)

b. Berusia di atas delapan belas (18) tahun

c. Tidak sedang sekolah atau kuliah (menempuh pendidikan normal)

\section{Tahapan-tahapan Pendaftaran Kartu Prakerja}

a. Tahapan Pertama

Langkah pertama yang dilakukan untuk mendaftar kartu prakerja:

1) Pergi ke https://dashboard.prakerja.go.id/daftar

2) Cek E-mail yang digunakan (disarankan menggunakan E-mail @gmail.com) Apabila tidak mendapatkan E-mail Verifikasi, maka dapat di peroleh melalui,

a) Cek di Spam

b) Cek apakah sudah menggunakan E-mail @gmail.com

c) Apabila masih belum mendapatkan E-mail verifikasi, bisa menunggu, atau bisa registrasi menggunakan e-mail baru

3) Klik Link Verifikasi yang diterima melalui Email

4) Verifikasi Berhasil. Jika Verifikasi tidak berhasil, Klik Verifikasi Ulang untuk mendapatkan e-mail Verifikasi baru. Kemudian klik Link di e-mail Verifikasi baru (kembali ke Step 3). Apabila tidak berhasil-berhasil, bisa register dengan e-mail baru (disarankan menggunakan@gmail.com)

5) Pergi ke: https://dashboard.prakerja.go.id/masuk

6) Masukkan NIK, KK dan tanggal lahir

7) Isi data-data diri, Upload Gambar KTP dan Selfie KTP

8) Verifikasi menggunakan nomor $\mathrm{Hp}$

9) Ikuti Test Kompetensi, Pilih Gelombang yang ingin diikuti

Menurut penuturan Ibu Ayu Masyarakat Desa

Patampanua waktu pertama kali Ibu Ayu mendaftar kartu prakerja ia mendaftar melalui dashboard kartu prakerja untuk membuat akun. Kemudian ketika Ibu Ayu mendaftar Ibu Ayu memasukkan emailnya yang aktif karena akan dikirimkan email konfirmasi dari pihak kartu prakerja. Setelah itu barulah kita bisa daftar kartu prakerja dan memasukkan nomor induk kependudukan (NIK) dan nomor kartu keluarga (KK) dan melengkapi semua yang disediakan oleh pihak kartu prakerja seperti tanggal lahir, alamat dan lain sebagainya. Dan Ibu Ayu juga memasukkan nomor handphone yang aktif.

b. Tahapan Kedua

Setelah dinyatakan lulus seleksi kartu prakerja, selanjutnya peserta di harapkan untuk mengikuti pelatihan guna untuk mendapatkan insentif. Pelatihan yang tersedia di masa pandemi ini yaitu pelatihan secara daring (dengan menonton vidio pelatihan, zoom, serta mengikuti pretes dan postes). Adapun langkah-langkah yang harus dilakukan untuk mendapatkan insentif yaitu:

1) Menyambungkan rekening peserta yang dinyatakan lulus dengan akun prakerja. Rekening yang tersedia yaitu bank BNI atau Ewallet (Linkaja, Ovo, Go-Pay dan Dana)

2) Membeli pelatihan dengan menggunakan saldo yang di sediakan oleh prakerja. Adapun besaran saldo yang disediakan yaitu Rp. 1.000.000. Saldo pelatihan ini hanya dapat digunakan untuk membeli pelatihan dan tidak dapat diuangkan. Ketika saldo pelatihan masih ada yang tersisa maka peserta dapat menggunakannya kembali untuk melakukan pembelian pelatihan baru. Namun jika tidak digunakan sampai bataswaktu yang disiapkan, maka saldo pelatihan yang tersisa akan di kembalikan ke khas Negara.

3) Mengikuti pelatihan yang sudah di dipilih sampai selesai. Pelatihan dinyatakan selesai ketika sertifikat pelatihan sudah terbit. Jika pelatihan tidak di selesaikan sampai batas waktu yang tersedia maka peserta kartu prakerja tidak berhak menerima insentif.

4) Setelah (tujuh) 7 hari kerja pelatihan dinyatakan selesai, maka akan muncul jadwal pencairan insentif bagi tiap peserta kartu prakerja. Adapun besaran insentif yang diterima yaitu sebesar Rp. 600.000/ bulan selama 4 bulan berturut-turut.

5) Beberapa setelah insentif pertama di cairkan, maka akan muncul survei pertama di Dashbord prakerja. Ketika peserta kartu prakerja mengisi survei, maka mereka berhak menerima insentif tambahan sebesar Rp. 50.000. Survei ini akan muncul sebanyak 3 kali, sehingga jumlah insentiif dari survei yang diterima yaitu $\mathrm{Rp}$. 150.000 .

Dari hasil wawancara Ibu Sakinah Masyarakat Desa Patampanua yaitu waktu Ibu Sakinah lulus kartu prakerja Ibu sakinah langsung menyambung e-wallet. Pada saat itu Ibu Sakinah memakai e-wallet OVO. Setelah itu akan masuk saldo 1 juta ke akun prakerja kita untuk membeli pelatihan, saldo 1 juta itu tidak bisa dicairkan melainkan hanya untuk dipakai untuk membeli pelatihan saja. Jika ingin mendapatkan 
instentif dari kartu prakerja Ibu Sakinah harus menyelesaikan pelatihannya yang telah dipilih dan dibeli kemudian jika sudah mendapatkan sertifikat dari platfom yang ditempati membeli pelatihan barulah bisa mendapatkan insentif yang beberapa hari kemudian akan muncul di dashboard kartu prakerja. Waktu lamanya pencairan bisa dilihat di dashboard kartu prakerja.

Di Desa Patampanua Kecamatan Matakali Kabupaten Polewali Mandar Sulawesi Barat dalam proses untuk mendapatkan bantuan kartu prakerja yaitu sama dengan seluruh masyarakat Indonesia lainnya dengan melalui beberapa tahapan-tahapan dimulai dari pembuatan akun kartu prakerja sampai dengan menerimanya insentif kartu prakerja jika sudah mengikuti dan mendapatkan sertifikat dari platfom yang diikuti pelatihannya.

Tabel 4.6 Penerima Kartu Prakerja

\begin{tabular}{|c|c|c|c|}
\hline NO & $\begin{array}{l}\text { Nama Penerima } \\
\text { Kartu Prakerja }\end{array}$ & Dusun & Tahun \\
\hline 1 & Sakinah & Rea Jaya & 2020 \\
\hline 2 & Ayu & Bulu Bawang & 2020 \\
\hline 3 & Irma & Rea Jaya & 2020 \\
\hline 4 & Arif & Rea Jaya & 2020 \\
\hline 5 & Saing & Rea Barat & 2020 \\
\hline 6 & Sulaiman & Rea Jaya & 2020 \\
\hline 7 & Warliah & Bulu Bawang & 2020 \\
\hline 8 & Muliati & Bulu Bawang & 2020 \\
\hline 9 & Rahim & Bulu Bawang & 2020 \\
\hline 10 & Abdullah & Rea Jaya & 2020 \\
\hline 11 & Wahida & Sappoang & 2020 \\
\hline 12 & Setiawati & Sappoang & 2020 \\
\hline 13 & Sarman & Rea Jaya & 2020 \\
\hline 14 & Askar & Rea Barat & 2020 \\
\hline 15 & Wahyu & Rea Barat & 2020 \\
\hline 16 & Samsul & Rea Barat & 2020 \\
\hline 17 & Amirullah & Bulu Bawang & 2020 \\
\hline 18 & Rizal & Rea Jaya & 2020 \\
\hline 19 & Suaib & Bulu Bawang & 2020 \\
\hline 20 & Sudirman & Rea Jaya & 2020 \\
\hline
\end{tabular}

Tabel di atas merupakan tabel penerima bantuan kartu prakerja di Desa Patampanua Kecamatan Matakali Kabupaten Polewali Mandar tahun 2020. Terdapat empat dusun yaitu Dusun Rea
Jaya, Rea Barat, Sappoang, dan Dusun Bulu Bawang pada tahun 2020. Dusun Rea Jaya terdiri dari delapan orang penerima kartu prakerja, Dusun Rea Barat terdiri dari empat orang penerima kartu prakerja, dan Dusun Sappoang terdiri dari dua orang yang penerima kartu prakerja, serta Dusun Bulu Bawang terdiri dari enam orang yang menerima kartu prakerja. Jadi total yang menerima kartu prakerja menurut tabel di atas 20 orang.

Efektivitas Bantuan Kartu Prakerja Terhadap Perekonomian Masyarakat di Masa Pandemi Covid 19 di Desa Patampanua Kecamatan Matakali Kabupaten Polewali Mandar

Kartu pra kerja diluncurkan sesuai dengan Peraturan Presiden Nomor 36 Tahun 2020 tentang penanaman kapasitas tenaga kerja melalui program kartu pra kerja. Program Kartu Prakerja merupakan realisasi dari Pasal 27 ayat 2 UUD 1945 yang berbunyi: "Setiap warga negara berhak atas pekerjaan dan penghidupan yang bermartabat." Kartu Prakerja membekali peserta dengan dana Rp 3.550.000, yang rinciannya $\mathrm{Rp} 1.000 .000$, imbalan pasca pelatihan $\mathrm{Rp}$ 600.000 per bulan selama empat bulan, dan imbalan jasa kerja total Rp 150.000.

Kartu pra-kerja pada awalnya dirancang untuk mempersiapkan pekerja untuk berbagai keterampilan sosial. Ketika COVID-19 tiba di Indonesia, tujuan awal ini berubah. Banyak perusahaan tutup, banyak pekerja yang di-PHK, dan angka pengangguran terus meningkat. Pemerintah akhirnya memutuskan untuk memberikan perlindungan kepada mereka yang terkena PHK akibat pandemi.

Banyak juga masyarakat yang mengeluhkan program kartu pra kerja yang sudah dilaksanakan selama ini, namun hasilnya masih nihil (belum disetujui) karena registrasi ulang. Bahkan jika administrasi prakerja menyediakan cara untuk mengadu, jika peserta gagal 3 kali berturut-turut, unduh lampiran surat pernyataan, lalu isi dan kirim kembali.

Efektivitas adalah suatu kondisi yang menunjukkan sejauh mana rencana dan tujuan dapat dicapai. Semakin banyak rencana yang dapat dicapai, semakin efektif kegiatan yang dilakukan. Sama halnya dengan program kartu prakerja yang di terbitkan sejak april 2020, akan dikatakan efektif ketika penerima kartu prakerja sesuai dengan target yang dituju. Diketahui bahwa, di Desa Patampanua yang memiliki jumlah penduduk lumayan banyak di dominasi oleh para pemuda yang baru lulus sekolah dan warga yang belum bekerja. Hal ini diakibatkan oleh kondisi yang masih berada dimasa pandemi sehingga masyarakat disana kesullitan dalam mencari kerja. Kondisi pandemi ini yang mengharuskan kita dirumah saja juga menambah angka kemiskinan di daerah ini. Sehingga dengan adanya program kartu prakerja ini, mereka merasa terbantu. 
Dari hasil wawancara bersama masyarakat Desa Patampanua, Kecamatan Matakali, Kabupaten Polewali Mandar mereka menyatakan bahwa bantuan kartu prakerja tersebut membantu dalam hal untuk memenuhi kebutuhan sehari-hari saja akan tetapi untuk keefektifan bantuan kartu prakerja di Desa Patampanua Kecamatan Matakali Kabupaten Polewali Mandar kurang efektif karena bagi masyarakat di Desa Patampanua insentif yang didapat selama empat bulan hanya membantu perekonomian sementara sedangkan tuntutan ekonomi berjalan terus menerus.

Adapun aspek-aspek yang mempengaruhi tidak efektifnya bantuan kartu prakerja di Desa Patampanua Kecamatan Matakali Kabupaten Polewali Mandar yaitu:

1. Aspek Nominal

Pemberian insentif kartu prakerja setelah menyelesaikan pelatihan di platfom yang dipilih sebesar Rp 600.000,-bagi masyarakat di Desa Patampanua tidak cukup karena hanya digunakan untuk keperluan sehari-hari saja

2. Aspek Proses

Insentif kartu prakerja diterima hanya selama 4 bulan begitu sebentar bagi masyarakat Desa Patampanua.

3. Aspek Analisis

Pelatihan yang ada di platfom masingmasing kartu prakerja begitu banyak. Akan tetapi sebagian yang mengikuti pelatihan prakerja tidak begitu jeli melihat apa yang seharusnya diikuti. Sebagai contoh begitu banyak yang mengikuti pelatihan masak-masak atau cara membuat kue padahal sudah begitu banyak yang menjual kue di Desa Patampanua. Otomatis ketika yang mengikuti pelatihan masak-masak atau cara membuat kue akan nantinya menjual dan pasti berpengaruh dengan pemasukan atau penjualan kue orang yang sudah membuka usaha di Desa Patampanuan. Seharusnya mereka mengikuti pelatihan yang baru, yang tidak asal mengikuti pelatihan-pelatihan yang ada disediakan oleh platfom.

4. Aspek Sistem

Dalam pemberian kartu prakerja ada banyak kendala salah satunya prakerja yang dilakukan secara online banyak yang terkendala di jaringan yang terkadang sulit. Seharusnya dilakukan secara langsung atau tatap muka agar lebih efektif dan peserta prakerja bisa mengetahui apa-apa saja yang seharusnya di ambil dalam pelatihan tersebut dan jika dilakukan secara langsung juga harus mengikuti protokol kesehatan.

Jadi dapat dikatakan bahwa bantuan kartu prakerja selama masa pandemi covid-19 di Desa Patampanua Kecamatan Matakali Kabupaten Polewali Mandar kurang efektif karena masyarakat hanya menggunakan bantuan kartu prakerja untuk memenuhi kebutuhan sehari-hari saja dan hanya selama empat bulan mendapatkan insentif, selain itu, program kartu prakeja ini, hanya dapat dimanfaatkan bagi masyarakat yang memiliki ilmu pengetahuan teknologi dan informasi (IPTEK) yang cukup. Hal ini di karenakan pendaftaran dan pelaksanaan program kartu prakerja ini menggunakan metode Daring. Sehingga masyarakat yang tidak tahu menahu tentang IPTEK akan terkendala pada program kartu prakerja.

\section{SIMPULAN}

Berdasarkan hasil penelitiaan dari penelitian ini dapat disimpulkan bahwa:

a. Proses bantuan kartu prakerja terhadap perekonomian masyarakat di masa pandemi covid19 di Desa Patampanua yaitu memiliki tahapantahapan. Tahapan Pertama pergi ke https://dashboard.prakerja.go.id/daftar, Cek E-mail yang digunakan, verifikasi berhasil, pergi $\mathrm{ke}$ : https://dashboard.prakerja.go.id/masuk, masukkan NIK, KK dan tanggal lahir, Isi data-data diri, upload gambar KTP dan selfie KTP, verifikasi menggunakan nomor $\mathrm{Hp}$, dan ikuti test kompetensi, pilih gelombang yang ingin diikuti. kemudian tahapan keduamenyambungkan rekening peserta yang dinyatakan lulus dengan akun prakerja. Rekening yang tersedia yaitu bank BNI atau Ewallet (Linkaja, Ovo, Go-Pay dan Dana), membeli pelatihan dengan menggunakan saldo yang di sediakan oleh prakerja, mengikuti pelatihan yang sudah di dipilih sampai selesai, setelah (tujuh) 7 hari kerja pelatihan dinyatakan selesai, maka akan muncul jadwal pencairan insentif bagi tiap peserta kartu prakerja.

b. Efektivitas bantuan kartu prakerja terhadap perekonomian masyarakat di masa pandemi covid19 di Desa Patampanua Kecamatan Matakali Kabupaten Polewali Mandar kurang efektifkarena masyarakat hanya menggunakan bantuan kartu prakerja untuk memenuhi kebutuhan sehari-hari saja dan hanya selama empat bulan mendapatkan insentif, selain itu, program kartu prakeja ini, hanya dapat dimanfaatkan bagi masyarakat yang memiliki ilmu pengetahuan teknologi dan informasi (IPTEK) yang cukup. Hal ini di karenakan pendaftaran dan pelaksanaan program kartu prakerja ini menggunakan metode Daring. Sehingga masyarakat yang tidak tahu menahu tentang IPTEK akan terkendala pada program kartu prakerja.

\section{DAFTAR PUSTAKA}

Hasbar, Mustfa dan Agung Wijaya. 2016. Efektivitas Pemungutan Pajak Bumi dan Bangunan Perdesaan Perkotaan (PBB-P2) Dengan Pendekatan Strategi SWOT Analysis Di Kabupaten Enrekang. E-Jurnal. 
Khoiriyah, Fatkhul. 2020. Efektivitas Pelaksanaan Bantuan Sosial dari Pemerintah Terhadap Masyarakat Terdampak Covid-19 di Desa Gendongarum Kecamatan Kanor Kabupaten Bojonegoro. Jurnal. Surabaya: Fakultas Syariah dan Hukum.

Makmur. 2015 Efektivitas Kebijakan Kelembagaan Pengawansan. Cet. II; Bandung: Refika Aditama.

Mufida, Saleha dkk. 2020. Strategi Pemerintah Indonesia dalam Menangani Wabah Covid-19 dari Perspektif Ekonomi. Jurnal. Bogor: Fakultas Strategi Pertahanan Universitas Pertahanan.

Nugroho, Rahmat Bayu. 2020. Dampak Covid-19 Bagi Kegiatan Ekonomi Masyarakat. Banjarmasin: FKIP ULM.

Prastowo, Andi. 2014. Metode Penelitian Kualitatif Dalam Perspektif Rancangan Penelitian. Jogjakarta: Ar-Ruzz Media.

Putri, Mutik Aromsin dkk. 2020. Dampak Covid-19 Pada Perekonomian Masyarakat Indonesia. Jurnal. Surakarta: Fakultas Ilmu Kesehatan Universitas Duta Bangsa Surakarta.

Situs Resmi Website Program Kartu Prakerja. 2020. www.prakerja.co.id. diakses Tanggal 19 Februari 2020.

Tim Prima Pena. 2015. Kamus Terbaru Ekonomi \& Bisnis. Cet. 1. Surabaya: Gitamedia Press.

Yamali, Fakhrul Rozi dan Ririn Noviyanti Putri. Dampak Covid-19 Terhadap Perekonomian Indonesi. 2020. Jambi: LPPM Universitas Batanghari. 